\title{
A preliminary study on several Lily cross-breeding experiment
}

\author{
Yu Yang, Yu Haijiao \\ Hainan Provincial Highway Survey and Design Institute,Haikou,Hainan,Chinal
}

Keywords: crossing; pollination method; analysis

\begin{abstract}
Test materials of ten different varieties, depending on the color and cold resistance to breeding new varieties. Use conventional crossing between Asia lily hybrids. Using and comparison analysis three different crossing methods between the Asian and Oriental Lily. The results showed that the hybrid lily species different crossing methods for different Hybrid Combination between the variety of lily.

Lily is a liliaceous (Liliaceae) (Lilium) of Lilium perennial bulbous flower, it is one of the world famous flowers. Lilium plant have a total of more than 90 wild species, we have 47 wild species in China [1]. At the beginning of 20th Century, we carry out the work of breeding of lily and created thousands of new varieties in Holland, Japan and America abroad as the center, but the excellent product only hundred varieties of cut flowers. Lily breeding work late in our country, the earliest gardens in Shanghai by Huang Jiming bred King lily * David lily bred by distant hybrid [2], after Huang Jiming etc have been reported from distant hybrid [3], Yang Liping reported that seven new strains of cold lily [4], but there was not bred a commercial cut flower varieties. In this experiment as 10 kinds of cut lily varieties as materials, the purpose is that according to the different colors and cold resistance to breeding new varieties.
\end{abstract}

\section{Materials and methods}

\subsection{Selection of parents}

Selected for the Asian parents lily's is A1 Brunello,A2 Navona,A3 Prato, A4 Cedeazzle, A5 Pollyanna, A6 Elite, Oriental Lily O1 Siberia, O2 Sorbonne, O3 Yelloween and A7 L.Lancifolium. Test on 6-10 months in 2007 at the Northeast Agricultural University Xiangfang experimental practice base.

\subsection{Experimental method}

The hybridization between different varieties of the same hybrid system by the conventional methods of hybridization, hybridization between different varieties in different hybrids adopted three methods were used for hybridization.

Cut style pollination in female (before blossom bud through color will be open when the emasculation bagging). Cross cut in the female, the style base, cut style pollination method vanTuyl[5] proposed cutting length, at a distance of $2 \mathrm{~mm}$ sub roof cutting, slitting knife in cross section, decorated with fresh pollen. Pollination time is in the morning 8:00-10:00, after pollination immediately bagging, hang tags, male, female, indicating the time of pollination. The number of flowers per pollination combinations are 50 flowers. After pollination remove paper bags, and began to observe the growth and development of ovary.

Mentor method pollination is with methanol treated compatible pollen and incompatible pollen and stigma above award in the female. Stigma smeared $0.1 \%$ NAA on pollination before female stigma smeared on the $0.1 \% \mathrm{NAA}$, and then taught to pollen.

\section{Result Analysis}

\subsection{Conventional hybridization between different varieties of Lily}

The selection of Asian lily hybrid combination according to different color, different varieties of Lilium Asiatic hybrid, due to the relatively close genetic relationship, therefore, hybridization between varieties is easy to success. The results are shown in table 1 : 


\begin{tabular}{|c|c|c|c|c|}
\hline $\begin{array}{r}\text { Hybrid } \\
\text { Combination }\end{array}$ & $\begin{array}{l}\text { The Number } \\
\text { of Pollinated } \\
\text { Flowers }\end{array}$ & $\begin{array}{l}\text { The Number } \\
\text { of Inflated Ovary }\end{array}$ & $\begin{array}{c}\text { Rate of } \\
\text { Inflated ovary(\%) }\end{array}$ & $\begin{array}{l}\text { The Number } \\
\text { of average seed }\end{array}$ \\
\hline $\mathrm{A} 1 \times \mathrm{A} 2$ & 50 & 10 & 20.0 & 14.3 \\
\hline $\mathrm{A} 1 \times \mathrm{A} 4$ & 50 & 37 & 74.0 & 10.5 \\
\hline $\mathrm{A} 1 \times \mathrm{A} 5$ & 50 & 25 & 50.0 & 9.6 \\
\hline $\mathrm{A} 2 \times \mathrm{A} 3$ & 50 & 33 & 66.0 & 9.7 \\
\hline $\mathrm{A} 2 \times \mathrm{A} 4$ & 50 & 28 & 56.0 & 11.3 \\
\hline $\mathrm{A} 2 \times \mathrm{A} 5$ & 50 & 15 & 30.0 & 6.4 \\
\hline $\mathrm{A} 2 \times \mathrm{A} 6$ & 50 & 15 & 30.0 & 5.8 \\
\hline $\mathrm{A} 3 \times \mathrm{A} 4$ & 50 & 18 & 36.0 & 8.6 \\
\hline $\mathrm{A} 3 \times \mathrm{A} 5$ & 50 & 18 & 36.0 & 6.3 \\
\hline $\mathrm{A} 3 \times \mathrm{A} 6$ & 50 & 17 & 34.0 & 4.6 \\
\hline $\mathrm{A} 4 \times \mathrm{A} 6$ & 50 & 38 & 76.0 & 3.8 \\
\hline $\mathrm{A} 5 \times \mathrm{A} 6$ & 50 & 32 & 64.0 & 11.6 \\
\hline
\end{tabular}

Note: the number of average seeds are the average number of all the mature embryo of seeds and all the number of Inflated Ovary

The results can be seen in table 1: hybrid between different varieties of Asiatic Lilium, the ovary swelling rate and average seed number differences, this difference may be due to a certain stage of hybrid embryo development was inhibited and not mature, there are great differences in the average seed number and expanding sub real number, it also shows that the mature some parts of the room. The seed is not very high, this may be the result of post fertilization barriers and not fully developed.

\subsection{Effects of different pollination methods on the seed setting rate of hybridization}

Hybridization of Asian lily different varieties and Oriental lily different varieties belong to distant hybridization, according to the literature review, this study aimed at the incompatibility of Asian lily and Oriental lily by three different methods of cross pollination. At the first the different cross combinations are divided into 3 different areas, this is to repeat ensure the test, to ensure the number of plants in each district to meet the need of plant number of pollination, the results are shown in table 2:

\begin{tabular}{|c|c|c|c|c|}
\hline $\begin{array}{c}\text { Hybrid } \\
\text { Combination }\end{array}$ & $\begin{array}{l}\text { Pollination } \\
\text { methods }\end{array}$ & $\begin{array}{l}\text { The } \\
\text { Number of } \\
\text { Inflated Ovary }\end{array}$ & $\begin{array}{l}\text { The } \\
\text { Number of } \\
\text { Inflated Ovary }\end{array}$ & $\begin{array}{l}\text { The } \\
\text { Number of } \\
\text { Inflated Ovary }\end{array}$ \\
\hline \multirow[t]{3}{*}{$\begin{array}{l}\text { Siberia } \times \text { Dazz } \\
\text { ling }\end{array}$} & $\begin{array}{l}\text { Cutting stigma } \\
\text { pollination method }\end{array}$ & 12 & 10 & 10 \\
\hline & $\begin{array}{c}\text { Mentor } \\
\text { pollination method }\end{array}$ & 8 & 8 & 6 \\
\hline & $\begin{array}{l}\text { Stigma } \\
0.1 \% \mathrm{NAA}\end{array}$ & 4 & 2 & 4 \\
\hline \multirow[t]{3}{*}{$\begin{array}{l}\text { Sorbonne } \times A \\
\text { nna }\end{array}$} & $\begin{array}{l}\text { Cutting stigma } \\
\text { pollination method }\end{array}$ & 10 & 8 & 6 \\
\hline & $\begin{array}{c}\text { Mentor } \\
\text { pollination method }\end{array}$ & 2 & 2 & 4 \\
\hline & $\begin{array}{l}\text { Stigma } \\
0.1 \% \mathrm{NAA}\end{array}$ & 6 & 6 & 8 \\
\hline \multirow[t]{2}{*}{$\begin{array}{c}\text { Yellow } \\
\text { storm } \times \text { succinct }\end{array}$} & $\begin{array}{l}\text { Cutting stigma } \\
\text { pollination method }\end{array}$ & 2 & 4 & 4 \\
\hline & Mentor & 10 & 12 & 10 \\
\hline
\end{tabular}


pollination method

Cutting stigma

6

6

pollination method

The two factor randomized block analysis of variance and Duncan multiple comparison analysis of Lilium Asiatic hybrids and Oriental hybrids combinations and different pollination methods, set the combinations as A factor, pollination $\mathrm{r}$ method as B factor, the results are shown in Table 3 and table 4:

Table 3. A Factor for Duncan Multiple Comparison Results

\begin{tabular}{cccc}
\hline A Factor & B Factor & $5 \%$ & $\begin{array}{c}1 \% \text { extremely } \\
\text { significant level }\end{array}$ \\
\hline A1 & B1 & significance level & A \\
& B2 & b & B \\
& B3 & c & C \\
A2 & B1 & a & A \\
& B3 & a & B \\
& B2 & b & A \\
A3 & B2 & a & B \\
& B3 & b & C \\
\hline
\end{tabular}

The results showed that the three combinations suitable for different pollination methods, The comparison results of A1 showed that B1, B3, and B2 had extremely significant difference, B2 and B3 significantly, the hybrid A1 is more suitable for cutting stigma pollination.The comparison results of A2 showed that B1, B3, and B2 had extremely significant difference, B1 and B3 have no significant difference, the hybrid A2 is more suitable for cutting stigma pollination. The comparison results of A3 showed that B2, B1, and B3 had extremely significant difference, B3 and B1 had extremely significant difference, A3 is more suitable for mentor pollination.

Table 4. B Factor for Duncan Multiple Comparison Results

\begin{tabular}{|c|c|c|c|}
\hline B Factor & A Factor & $\begin{array}{c}5 \% \\
\text { significance level }\end{array}$ & $\begin{array}{c}1 \% \text { extremely } \\
\text { significant level }\end{array}$ \\
\hline \multirow[t]{3}{*}{ B1 } & A1 & $\mathrm{a}$ & A \\
\hline & A2 & b & A \\
\hline & A3 & C & B \\
\hline \multirow[t]{3}{*}{ B2 } & A3 & $\mathrm{a}$ & A \\
\hline & $\mathrm{A} 2$ & b & B \\
\hline & A1 & C & $\mathrm{C}$ \\
\hline \multirow[t]{3}{*}{ B3 } & A2 & $\mathrm{a}$ & A \\
\hline & A3 & a & $A B$ \\
\hline & A1 & b & $\mathrm{AC}$ \\
\hline
\end{tabular}

The results showed that the three kinds of pollination methods on the three hybrid combinations showed significant differences, compared to the results of B1showde that A2, A1 and A3 had significant difference, A2 and A3 were significant differences, for cutting stigma pollination was the best performance in the hybrids of A1. The comparison results of B2 showed that A3, A1, and A2 had extremely significant difference, there was significant difference between A2 and A1, the mentor method pollination method in hybrid A3 performed better than A2, A2 is better than that of A1 group. For the results of B3 showed that A2, A3 and A1 had significant difference, A2 and A3 have no significant difference, indicating the stigma pollination method with $0.1 \%$ NAA in A2 and A3 were better than that of A1 group.

\section{Discussion}

In the hybrid breeding of lily, we can clearly see that there are serious obstacles. In general, it 
can be divided into pre fertilization barrier, the barrier post fertilization barriers in two cases. Pre fertilization barriers in pollen germination and pollen tube elongation in the process, the degree of disorder and can be divided into the upper and lower inhibition inhibition style: two cases. Post fertilization barriers, mainly in the fertilized embryo development is not complete, incomplete development of hybrid seed. The disorder may be due to the incompatibility of embryo and endosperm hybrids, the hybrid embryo abortion in early.

Between different Asian Lily Cultivars in this study belong to a hybrid system using hybrid method of conventional hybridization incompatibility is relatively small, but the real swell ratio and average seed number, the effect is also good, but for the hybridization between Asiatic hybrids and oriental lily belongs to the interspecific hybridization, generally uses the method of cutting pollination to overcome [6], the hybrid method is very difficult to obtain the conventional hybrids, often occurs before fertilization barriers, so in view of this situation, this study used three different pollination methods, and has carried on the comparison and analysis, test results show that, cut style pollination method is not for all combinations it is applicable to the other two methods, we also received very good results for different combinations, so we should according to the different cross combinations with different hybridization methods, this study remains to be the next step.

\section{Reference:}

[1]. Cheng J S. Genetics and breeding of garden plants Beijing China Forestry Publishing House,2000 309-311(in Chinese)

[2]. Huang J M Cultivation of intetspecific hybrids between Lilium regale and L davidii Acta Horticulturae sinica,1982,9(3):51-56(in Chinese)

[3]. Huang J M, Zhao X Y, Zhang G M, Ni Y Y. Interspecific hybrids by using Lilium amoenum as pollen parent Acta Horticulturae Sinica,1990,17(2):153-156( in Chinese)

[4]. Yang L P, Liu G F, Zhang Y N. The breed of strains with resistance for lily. Journal of Northeast Forestry University 2003 31(6)1:33-35(in Chinese)

[5]. Tuyl J M Van, Claramarcucci M,Visser T. Pollen and pollination experiments:VII.The effect of pollen treatment and application method on incompatibility and incongruity in Lilium [J].Euphytica,1982,31:613-619

[6]. Ascher P D.\&L W Drewlow. The effect of prepollination injection with stigmatic exudatation interspecific pollen tube growth in Lilium longiflorum [J]. THUMB. styles. Plant Sci. Letters., 1975, 4:401-405. 